\title{
Tumor orbitário como primeira manifestação clínica de mieloma múltiplo: relato de caso
}

\author{
Orbital tumor as the first clinical manifestation of multiple myeloma: case report
}

\author{
Aline Ruilowa de Pinho' \\ Eliana Alcanfor de Pinho ${ }^{2}$ \\ Euripedes Figueiredo Alessandri ${ }^{3}$ \\ Luciano Sousa Pereira ${ }^{4}$
}

\begin{tabular}{|c|}
\hline RESUMO \\
\hline O acometimento da órbita pelo mieloma múltiplo é raro. Neste estudo, os \\
autores descrevem um caso infrequente de proptose como primeiro sinal \\
clínico do mieloma múltiplo. A presença de lesão orbitária expansiva \\
associada a destruição do rebordo superior da órbita, notáveis à tomografia \\
computadorizada, fez com que a diagnóstico de mieloma múltiplo fosse \\
considerado. Aspectos diagnósticos e terapêuticos são discutidos. \\
\hline
\end{tabular}

Descritores: Mieloma múltiplo; Exoftalmia; Tomografia computadorizada por emissão; Relato de casos [Tipo de publicação]

\section{INTRODUÇ̃̃̃O}

O mieloma múltiplo (MM) é uma neoplasia plasmocitária que representa $10 \%$ dos cânceres hematológicos ${ }^{(1)}$. Caracteriza-se por lesões ósseas destrutivas em múltiplos locais, insuficiência da medula óssea e produção de proteína monoclonal ${ }^{(1-2)}$. O comprometimento ocular é infrequente, na maioria das vezes se manifestando como cistos de íris e corpo ciliar e alterações vasculares retínicas ${ }^{(2-4)}$.

$\mathrm{O}$ acometimento da órbita pelo MM é raro, com menos de 50 casos descritos na literatura, nenhum deles em língua portuguesa ${ }^{(2-3,5-7)}$. Neste estudo, descrevemos um caso infrequente de tumor orbitário como primeira manifestação do MM, discutindo aspectos diagnósticos e terapêuticos.

Trabalho realizado na Fundação Banco de Olhos de Goiás - FUBOG - Goiânia (GO) - Brasil.

${ }^{1}$ Residente de Oftalmologia da Fundação Banco de Olhos de Goiás - Goiânia (GO) - Brasil.

${ }^{2}$ Médica assistente do Departamento de Oftalmologia da Santa Casa de Misericórdia de Goiânia e do Instituto Pan-americano da Visão - Goiânia (GO) - Brasil.

${ }^{3}$ Doutor em Oftalmologia pela Universidade Federal de Minas Gerais - UFMG - Belo Horizonte (MG) - Brasil. Médico oftalmologista do Instituto Pan-americano da Visão - Goiânia (GO) - Brasil.

${ }^{4}$ Ophthalmic Plastic \& Reconstructive Surgery and Neuro-ophthalmology Hearstfellow - University of California, San Francisco, USA. Médico oftalmologista do Instituto Pan-americano da Visão - Goiânia (GO) Brasil.

Endereço para correspondência: Luciano Sousa Pereira. Av. T-5, nº 150 - setor Bueno, Goiânia (GO) CEP 74230-040

Email: lucianospereira@gmail.com

Recebido para publicação em 25.03.2008

Aprovação em 17.11.2008

\section{RELATO DE CASO}

Paciente de 55 anos do sexo feminino, parda, deu entrada na Fundação Banco de Olhos de Goiás, com história de desvio progressivo do olho esquerdo para baixo com cinco meses de evolução.

Ao exame, apresentava, no olho esquerdo, acuidade visual de conta dedos a 2 metros, defeito pupilar aferente relativo (1,2 log) e proptose com desvio inferior do bulbo ocular (Hertel com base de $100 \mathrm{~mm}: 18 \mathrm{~mm}$ OD, 25 mm OE) (Figura 1). À palpação, observava-se massa tumoral na região superior da órbita, de consistência mole, imóvel, dolorosa e com ausculta silenciosa. Não foram observadas alterações biomicroscópicas e a medida da pressão intraocular foi de $22 \mathrm{mmHg}$. À oftalmoscopia indireta foi constatada a presença de edema de disco óptico, hemorragias peridiscais e dobras de coróide. O exame do olho direito encontrava-se inalterado, com acuidade visual de 20/20 e medida da pressão intraocular de $15 \mathrm{mmHg}$.

Tomografia computadorizada (TC) de órbita evidenciou lesão expansiva na região superior da órbita esquerda associada a lesões líticas do
\end{abstract}




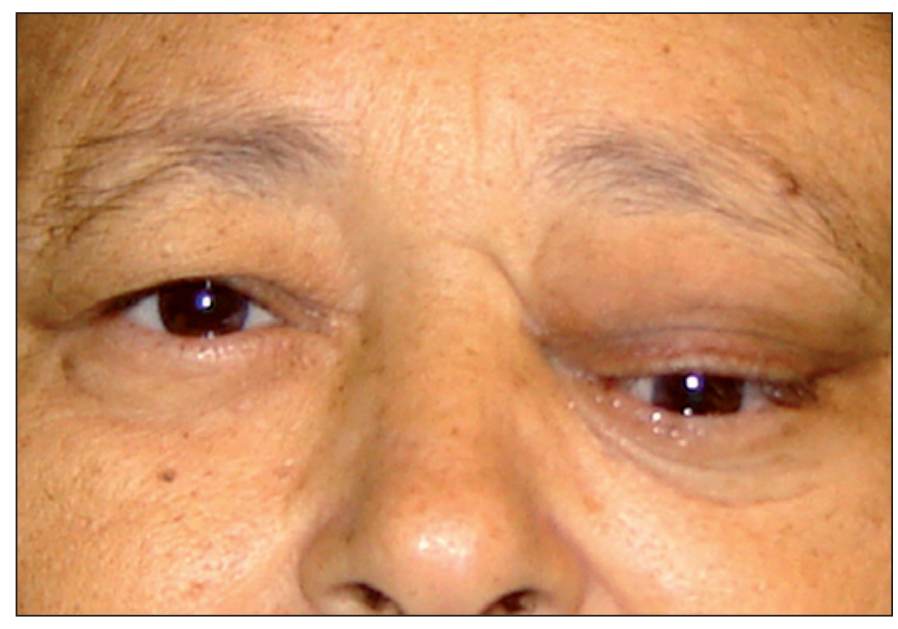

Figura 1 - Proptose e desvio do olho esquerdo para baixo em paciente com mieloma múltiplo de órbita

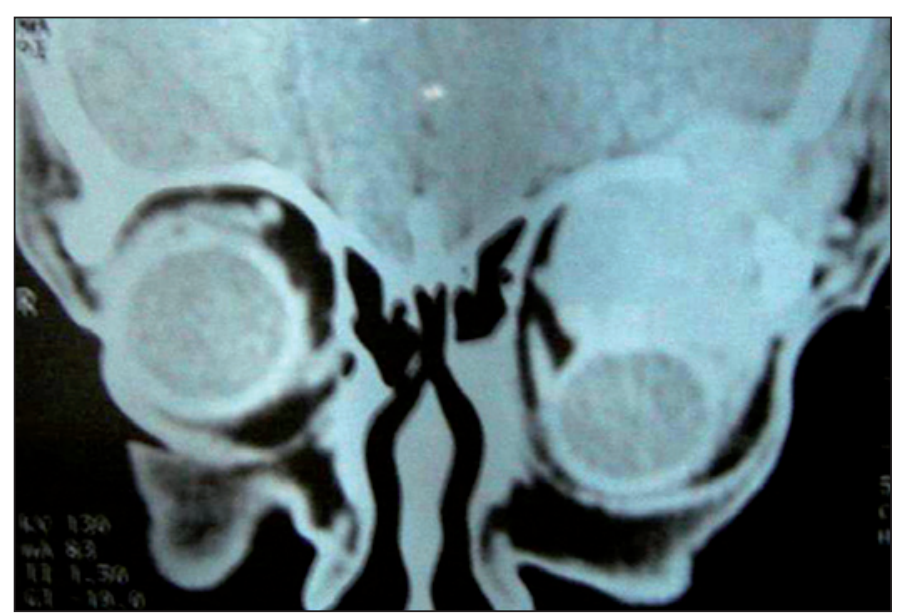

Figura 2 - Mieloma múltiplo de órbita - tomografia computadorizada, corte coronal. Observa-se lesão expansiva acometendo órbita superior esquerda, associada a osteólise do rebordo orbitário superior e invasão do espaço intracraniano.

rebordo orbitário, com intensa captação de contraste (Figura 2). Radiografia de coluna vertebral evidenciou colapso parcial do corpo vertebral em L2.

Velocidade de hemossedimentação (112 mm - $1^{\underline{a}}$ hora) e níveis séricos de cálcio $(13,6 \mathrm{mg} / \mathrm{dl})$, uréia $(73 \mathrm{mg} / 100 \mathrm{ml})$ e creatinina $(3,6 \mathrm{mg} / \mathrm{dl})$ encontravam-se elevados. Foi observada também anemia normocítica e normocrômica, além de alterações hidroeletrolitícas compatíveis com quadro de insuficiência renal.

Mielograma evidenciou a presença de $45 \%$ de plasmócitos, compatível com quadro de mieloma. A imunoeletroforese de proteínas detectou bandas monoclonais com Anti-IgA e anti-KAPPA, compatíveis com mieloma múltiplo por IgA. O perfil eletroforético mostrou-se alterado com a proteína mielomatosa representando $7,4 \%(0,44 \mathrm{~g} / \mathrm{dl})$ do total de proteínas $(6 \mathrm{~g} / \mathrm{dl})$.

O tumor foi estadiado no grupo IIIB e tratamento quimioterápico clássico com vincristina, adriamicina e dexametaso- na foi iniciado, além de medidas para controle da insuficiência renal. A paciente respondeu de forma insatisfatória ao tratamento e, após segundo ciclo de quimioterapia, evoluiu para óbito por insuficiência renal.

\section{DISCUSSÃO}

O MM é uma neoplasia maligna rara que afeta adultos acima de 40 anos, com discreta predominância em pacientes do sexo masculino, sendo duas vezes mais frequente em negros do que em brancos ${ }^{(1)}$.

O envolvimento da órbita por tumores de células plasmáticas é raro. Numa revisão de 2.000 casos de tumores orbitários, alguns autores encontraram apenas cinco plasmocitomas; destes, somente um apresentou envolvimento e destruição da margem orbitária ${ }^{(7)}$. Os autores desconhecem casos de MM orbitário publicados na literatura científica brasileira.

Os critérios para o diagnóstico de mieloma múltiplo consistem em biópsia de medula óssea com plasmócitos acima de $10 \%$ ou presença de plasmocitoma e, no mínimo, um dos seguintes achados: 1) proteína monoclonal no soro; 2) proteína monoclonal na urina; 3) lesões osteolíticas ${ }^{(1,8)}$. Apesar de outros processos patológicos poderem causar destruição óssea das paredes orbitárias (neoplasias malignas de glândula lacrimal, condrosarcomas, osteosarcomas, adenocarcinoma de seios da face, mucoceles, cistos dermóides) ${ }^{(6)}$, a localização da lesão na margem orbitária superior associada a lesões líticas na coluna vertebral fizeram com que MM fosse suspeitado em nossa paciente. A confirmação diagnóstica foi obtida através do mielograma que apresentou $45 \%$ de plasmócitos. A maioria dos casos de $\mathrm{MM}$ apresentam pico monoclonal de IgG à imunofixação ${ }^{(1)}$. No nosso caso, a paciente apresentou pico monoclonal de IgA, o que ocorre em apenas $20 \%$ dos $\operatorname{casos}^{(1)}$.

O estadiamento clínico tem importante valor prognóstico e terapêutico em pacientes com MM. Em casos de MM assintomático não existem ainda evidências de que a instituição de tratamento precoce prolongue a taxa de sobre$\operatorname{vida}^{(8)}$. Nos casos de MM ativo e sintomático, dados recentes sugerem que novas associações de drogas possam ter resultados superiores aos do esquema clássico (vincristina, adriamicina e dexametasona), entre elas: talidomida com dexametasona e lenalidomida com dexametasona ${ }^{(8)}$. Nossa paciente, classificada no estadio III B - segundo método proposto por Durie \& Salmon ${ }^{(9)}$ - (Quadro 1), foi submetida à quimioterapia com o esquema clássico; porém, respondeu de forma insatisfatória, evoluindo a óbito após o segundo ciclo de quimioterapia por insuficiência renal. Infecções e insuficiência renal são as principais causas de morte em pacientes com MM.

Concluímos que, apesar de raro, proptose pode ser o primeiro sinal do mieloma múltiplo. Em casos de proptose associada a lesões líticas das paredes orbitárias, cabe ao 


\begin{tabular}{|c|c|}
\hline \multicolumn{2}{|c|}{ Quadro 1. Estadiamento de Durie \& Salmon para mieloma múltiplo ${ }^{(9)}$} \\
\hline Estadio & Critérios \\
\hline & Baixa massa tumoral $\left(<0,6\right.$ células $\left.\times 10^{12} / \mathrm{m}^{2}\right)$ \\
\hline I & $\begin{array}{l}\text { Todos os seguintes: } \mathrm{Hb}>10 \mathrm{~g} / \mathrm{dl} \text {; cálcio normal } \\
\mathrm{lgG}<5 \mathrm{~g} / \mathrm{dl} \text {, IgA }<3 \mathrm{~g} / \mathrm{dl} ; \text { proteína urinária } \\
\text { monoclonal }<4 \mathrm{~g} / 24 \mathrm{~h} \\
\text { Ausência ou lesão óssea única }\end{array}$ \\
\hline II & $\begin{array}{l}\text { Intermediário (entre os estádios II e III) } \\
\text { Alta massa tumoral }\left(1,2 \text { células } \times 10^{12} / \mathrm{m}^{2}\right)\end{array}$ \\
\hline III & $\begin{array}{l}\text { Qualquer um dos seguintes: } \\
\mathrm{Hb}<8,5 \mathrm{~g} / \mathrm{dl} \text {; cálcio }>12 \mathrm{mg} / \mathrm{dl} \text {; lgG }>7 \mathrm{~g} / \mathrm{dl} \text {, } \\
\mathrm{lgA}>5 \mathrm{~g} / \mathrm{dl} \text {; proteína urinária monoclonal }>12 \mathrm{~g} / 24 \mathrm{~h} \\
\text { Múltiplas lesões osteolíticas, fraturas }\end{array}$ \\
\hline Subclasse & $\begin{array}{l}\text { A - se creatinina }<2 \mathrm{mg} / \mathrm{dl} \\
\text { B - se creatinina } \geq 2 \mathrm{mg} / \mathrm{dl}\end{array}$ \\
\hline
\end{tabular}

oftalmologista suspeitar e investigar, em conjunto com o hematologista, a presença de mieloma múltiplo, uma vez que, nesses casos, o diagnóstico e o tratamento precoces são fatores decisivos para o prognóstico.

\section{ABSTRACT}

Orbital involvement by multiple myeloma is rare. In this study, the authors report an unusual case of proptosis as the first clinical sign of multiple myeloma. The presence of an orbital lesion expanding and destroying the superior orbital rim, disclosed by computed tomography, lead us to consider multiple myeloma. Diagnostic and therapeutic aspects are discussed.

Keywords: Multiple myeloma; Exophthalmos; Tomography, emission-computed; Case reports [Publication type]

\section{REFERÊNCIAS}

1. Rajkumar SV, Kyle RA. Plasma cell disorders. In: Goldman L, Ausiello D, editors. Cecil Textbook of Medicine. 23 ${ }^{\text {rd }}$ ed. Philadelphia: Saunders; 2007. p.1426-37.

2. Sharma A, Kaushal M, Chaturvedi NK, Yadav R. Cytodiagnosis of multiple myeloma presenting as orbital involvement: a case report. CytoJournal. $2006 ; 3: 19$.

3. Knapp AJ, Gartner S, Henkind P. Multiple myeloma and its ocular manifestations. Surv Ophthalmol. 1987;31(5):343-51.

4. Hedal Jr J, Malerbi FK, Melaragno Filho R. Trombose de veia central da retina bilateral associada à síndrome de hiperviscosidade sanguínea - relato de caso. Arq Bras Oftalmol. 2005;68(1):126-8.

5. Orellana J, Friedman AH. Ocular manifestations of multiple myeloma, Waldenström's macroglobulinemia and benign monoclonal gammopathy. Surv Ophthalmol. 1981;26(3):157-69.

6. Rootman J, White VA, Connors JM, Gascoyne RD. Lymphoproliferative, leukemic, and histiocytic lesions of the orbit. In: Rootman J. Diseases of the orbit - a multidisciplinary approach. $2^{\text {nd }}$ ed. Philadelphia: Lippincott Williams \& Wilkins; 2003. p.385-416.

7. Rodman HI, Font RL. Orbital involvement in multiple myeloma. Review of literature and report of three cases. Arch Ophthalmol. 1972;87(1):30-5.

8. Kyle RA, Rajkumar SV. Multiple myeloma. Blood. 2008;111(6):2962-72.

9. Durie BG, Salmon SE. A clinical staging system for multiple myeloma. Correlation of measured myeloma cell mass with presenting clinical features, response to treatment and survival. Cancer. 1975;36(3):842-54. 